\title{
Big data of clinical manifestations combined with neuroelectrophysiologic features in the early diagnosis of motor neuron disease
}

\author{
Nana Tian ${ }^{1,2}$ (D) Liyun Zhang ${ }^{1} \cdot$ Zunbo $\mathrm{Li}^{1} \cdot$ Jianjun Liu ${ }^{1} \cdot$ Guohua Lei ${ }^{1,2} \cdot$ Yanyan $\mathrm{Ma}^{1,2}$
}

Received: 15 June 2018 / Accepted: 27 September 2018 / Published online: 11 January 2019

(c) The Author(s) 2019

\begin{abstract}
Motor neuron disease/amyotrophic lateral sclerosis (ALS) is an adult-onset neurodegenerative disorder characterised by loss of upper motor neurons (including the Betz cells of the motor cortex), and lower motor neuron, anterior horn cells of the spinal cord and brainstem nuclei. 5-10\% in ALS is hereditary and sporadic, with an incidence of 2-3 per 100,000. ALS is a fatal disease. The average survival of patients is $3-5$ years. So far, the pathogenesis of ALS has been unclear. Although there are many drugs in the trial, there is no reversible treatment for motor neurons that are already degenerating. Although more and more researchers are investing a lot of energy in research, the time for identifying this disease is still very long. In the diagnosis of ALS patients, in order to obtain appropriate treatment and care, it is great significance of the concept of "the earlier the better" to diagnose. The purpose of this study was to explore factors for possible early diagnosis and potential therapeutic agents by reviewing the literature and collecting case data and discuss their potential for improvement. We retrospectively analyzed ALS patients from 23427 patients in department of neurology in Xi' an Gaoxin Hospital between December 2006 and March 2017. The conclusion displayed that early neurological electrophysiological examination combined with clinical features can improve the diagnosis of ALS.
\end{abstract}

Keywords Motor neuron disease · Amyotrophic lateral sclerosis · Diagnosis time · Neuroelectrophysiology

\section{Introduction}

MND/ALS is an adult-onset neurodegenerative disorder characterised by loss of upper motor neurons (UMNs, including the Betz cells of the motor cortex), and lower motor neuron (LMNs, anterior horn cells of the spinal cord and brainstem nuclei) (Bäumer et al. 2014). The term MND is largely synonymous with ALS, reflecting the observation that most patients demonstrate combined LMN-related loss

Nana Tian, Zunbo Li and Jianjun Liu contributed equally to this work and should be considered co-first authors.

Zunbo Li

1zb88031347@126.com

Jianjun Liu

ljjfzc57@vip.sina.com

1 Department of Neurology, Xi' an Gaoxin Hospital, Xi'an 710075, Shanxi, China

2 Xi' an Gaoxin Hospital Affiliated to Xi' an Medical College, Xi' an 710075, Shanxi, China of muscle as a result of denervation (amyotrophy), and UMN degeneration of the lateral corticospinal tract and its cortical origins manifesting as gliosis, or hardening (sclerosis). $5-10 \%$ in ALS is hereditary (fALS) and sporadic (sALS), with an incidence of 2-3 per 100,000 (Furuta et al. 2013). ALS is a fatal disease. The average survival of patients is 3-5 years (Electromyography 2012). Now that ALS is no longer a single disease that affects the motor nervous system, up to $15 \%$ have significant frontotemporal dementia (FTD) (Bäumer et al. 2014). So far, the pathogenesis of ALS has been unclear. Currently, only riluzole and edaravone have been approved for ALS treatment by the Food and Drug Administration (FDA). Riluzole can prolong the survival of patients with ALS for up to 2-3 months, and has little effect on quality of life. Edaravone mildly improves the patient's mobility, but the impact on survival is unknown (Chia et al. 2018). Although there are many drugs in the trial, there is no reversible treatment for motor neurons that are already degenerating.

Although more and more researchers are investing a lot of energy in research, the time for identifying this disease is 
still very long. In the diagnosis of ALS patients, in order to obtain appropriate treatment and care, it is great significance of the concept of "the earlier the better" to diagnose.

The purpose of this study was to explore potential therapeutic agents and factors for possible early diagnosis by reviewing the literature and collecting case data and discuss their potential for improvement.

\section{Objectives and methods}

\subsection{Objectives}

Retrospective analysis of ALS patients with from 23,427 patients in Department of Neurology in Xi' an Gaoxin Hospital from December 2006 to March 2017.

\subsection{Methods}

Collection of ALS patient gender, age of onset, time of diagnosis, first site, first symptom and neurophysiological data of ALS patients as part of clinical symptoms, including needle electromyographic data, motor nerve conduction data, and sensory nerve conduction data. The electrophysiological study of nerves was performed by the Danish Keypoint.net EMG apparatus.

Diagnostic time is defined as the interval between the time when the first symptom begins and the time when the diagnosis is confirmed (Sabrina et al. 2014; Paganoni et al. 2014; Simon et al. 2014; Chen and Fan 2014; Cellura et al. 2012).

The first time of the electrophysiological examination was defined as the interval between the time when the first symptom began and the first time electrophysiological examination was performed (Paganoni et al. 2014).

Each patient was used concentric EMG to record neurogenic changes including fibrillation potential and positive potential. Screening of limb muscles including deltoid, triceps, biceps brachii, abductor pollicis brevis (APB), first dorsal interosseous (FDI), abductor digiti minimi (ADM), quadriceps, tibialis anterior (TA) and musculus gastrocnemius (MG) ; Screening for extra muscles based on clinical performance. Screening of the sternocleidomastoid, trapezius, and lingualis when bulbus medullae was considered; T10 paraspinal muscle was selected in the thoracic spine. For comparative analysis, muscles were divided into proximal upper limbs (deltoid, biceps and triceps), distal upper limbs (APB, FDI, and ADM), and lower limbs (quadriceps, TA and MG). Upper and lower limb motor nerve conduction studies (NCS) include the median nerve, ulnar nerve, common peroneal nerve, and tibial nerve.

The dCMAP amplitude compares with the laboratory dCMAP normal limit (LLN).
The "split hand" is a characteristic of ALS patients. The first to shrink is the APB, FDI and ADM.

"Split hand" defines the ratio between the dCMAP amplitude of the median nerve (APB) and the dCMAP of the ulnar nerve (ADM) (APB: ADM). The ratio less than 0.6 is considered as evidence of "split hands" (Simon et al. 2014).

The clinical symptoms of each region were collected. The body regions were divided into four regions: bulbus medullae, cervical spinal cord, thoracic spinal cord, and lumbosacral spinal cord. The diagnostic level for each patient is based on the Awaji-shima diagnostic criteria (Electromyography 2012; Chen and Fan 2014).

\subsection{Statistical processing}

SPSS19.0 software package was used for data analysis. Measurement data with non-normal distribution are expressed as median (Md), and measurement data with normal distribution are expressed as $\bar{X} \pm \mathrm{S}$.

\section{Results}

\subsection{The clinical manifestations}

There were 56 patients with ALS in this group. There were 44 cases of clinically definite ALS, which accounted for $78.6 \%$ of the total number of cases (Tables 1,2). There were 7 cases of clinically probable ALS, which accounted for $12.5 \%$ of the total number of cases (Table 3 ). There were 5 cases of clinically possible ALS, accounting for $8.9 \%$ of the total number cases (Table 4). Clinical features combined with electromyographic examination made clinical diagnosis earlier. It improved 4 cases from clinically possible to clinically probable ( $7.1 \%$ of total cases); 6 cases from clinically probable to clinically definite ( $10.7 \%$ of total cases); 2 cases from clinically possible to clinically definite (3.6\% of total cases) (Tables 1, 2, 3, 4). 39 males and 17 females patients were in this group of ALS. The ratio of male to female was 2.3:1. Among them, $48.2 \%$ patients were cervical spinal cord onset, $23 \%$ bulbus medullae onset, $23 \%$ lumbosacral onset, no thoracic onset case and $7.1 \%$ patient were started atypical (fatigue, numbness and swelling of upper limb, muscle pain in lower limb, double leg sore) The onset age was between 10 and 72 , the mean age was $52.5 \pm 12.0$. The onset age in the bulbus medullae group was $56.2 \pm 13.0$, in the cervical spinal cord group was $54.3 \pm 8.6$, in the lumbosacral spinal cord group was $45.1 \pm 14.5$ (Table 5). The median time of total diagnosis was 12.5 months. The median time of diagnosis in the bulbus medullae group was 8 months; in the cervical spinal cord group was 12.5 months, in the 
Table 1 Clinical and electromyographic performance of 28 patients with clinically definite ALS

\begin{tabular}{|c|c|c|c|c|c|c|c|}
\hline Cases & $\begin{array}{l}\text { Bulbar } \\
\text { muscle }\end{array}$ & $\begin{array}{l}\text { Cervical } \\
\text { muscle }\end{array}$ & $\begin{array}{l}\text { Thoracic } \\
\text { muscle }\end{array}$ & $\begin{array}{l}\text { Lumbosacral } \\
\text { muscle }\end{array}$ & UMN & Symptomless muscle EMG abnormal & Diagnosis \\
\hline 1 & + & + & + & + & + & Trapezius & Clinically definite \\
\hline 2 & + & + & + & + & + & Biceps brachii & Clinically definite \\
\hline 3 & + & + & + & + & + & T10 paraspinal muscle & Clinically definite \\
\hline 4 & + & + & + & + & + & APB & Clinically definite \\
\hline 5 & + & + & + & + & + & APB FDI & Clinically definite \\
\hline 6 & + & + & + & + & + & TA MG & Clinically definite \\
\hline 7 & + & + & + & - & + & APB Deltoid biceps brachii & Clinically definite \\
\hline 8 & + & + & - & + & + & MG T10 paraspinal muscle & Clinically definite \\
\hline 9 & + & + & - & + & - & T10 paraspinal muscle & Clinically definite \\
\hline 10 & + & + & - & + & + & TA & Clinically definite \\
\hline 11 & + & + & - & + & + & T10 paraspinal muscle & Clinically definite \\
\hline 12 & + & + & - & + & + & T10 paraspinal muscle & Clinically definite \\
\hline 13 & + & + & - & + & - & T10 paraspinal muscle & Clinically definite \\
\hline 14 & + & + & - & + & + & T10 paraspinal muscle & Clinically definite \\
\hline 15 & + & + & - & + & + & Trapezius & Clinically definite \\
\hline 16 & + & + & - & + & + & Trapezius T10 paraspinal muscle & Clinically definite \\
\hline 17 & + & + & - & + & + & T10 paraspinal muscle & Clinically definite \\
\hline 18 & + & - & + & + & - & Biceps brachii & Clinically definite \\
\hline 19 & + & - & + & + & + & TA MG & Clinically definite \\
\hline 20 & + & + & - & - & + & TA MG sternocleidomastoid & Clinically definite \\
\hline 21 & + & + & - & - & + & TA MG sternocleidomastoid & Clinically definite \\
\hline 22 & + & - & - & + & + & Biceps brachii & Clinically definite \\
\hline 23 & + & - & - & + & - & FDI & Clinically definite \\
\hline 24 & - & + & - & + & - & Sternocleidomastoid & Clinically definite \\
\hline 25 & - & + & - & + & + & APB MG T10 paraspinal muscle & Clinically definite \\
\hline 26 & + & - & - & - & + & APB biceps brachii TA & Clinically definite \\
\hline 27 & - & + & - & - & + & TA trapezius T10 paraspinal muscle & Clinically definite \\
\hline 28 & - & + & - & - & - & Trapezius T10 paraspinal muscle & Clinically definite \\
\hline
\end{tabular}

Instructions: 1. The clinical manifestations of lower motor neurons (LMN) include limb weakness, muscle atrophy, and reduced or disappearance of tendon reflexes; the symptoms of bulbus medullae lower motor neurons (LMN) manifest as dysphagia, drinking water cough, speech slurs, lingual atrophy and fibrillation. EMG features of LMN are defined as: (1) Progressive muscle denervation potential: fibrillation and positive potentials. (2) Chronic denervation potential: Gaint potential (increased amplitude, widened duration) accompanied by plenty polyphase waves when muscle contracted slightly. Increased amplitude and reduced recruitment even interference waves when muscle contracted heavily. The dCMAP amplitude of the distal muscle was significantly decreased and the MCV (Motor nerve conduction velocity) slightly slowed. Upper motor neuron (UMN) damage performance: tendon hyperreflexia, pyramidal tract positive and so on. 2. "+": There are the above symptoms, signs, abnormal EMG performance

lumbosacral spinal cord group was 30 months (Table 6). The median time of diagnosis in 10-39 year-old group was 30.5 months; in 40-49 year-old group and 50-59 yearold group was 12 months; in 60-72 year-old group was 17.5 months (Table 7). The total misdiagnosis rate was $33.9 \%$, of which cerebral infarction accounted for $36.8 \%$; the misdiagnosis rate in the $60-72$ year-old group was as high as $64.3 \%$, of which $77.8 \%$ were misdiagnosed as cerebral infarction. The median time to first electrophysiological examination was 11 months.

\subsection{Electrophysiological data}

\subsubsection{Needle EMG}

Asymmetry of clinical and electrophysiological abnormalities is present in this group of patients with ALS. Among the 56 patients, there were 32 patients with asymptomatic muscle while EMG was abnormal. The abnormal rate was $57.14 \%$ (Tables 1,3 ). In this group of patients with ALS, different muscles have abnormal EMG while they are asymptomatic (Table 5). A total of 26 patients underwent electromyographic examination of T10 spinous paraspinal muscle. There were 12 cases 
Table 2 Clinical and electromyographic performance of 16 patients with clinically definite ALS
Table 3 Clinical and

electromyographic performance of 7 patients with clinically probable ALS
Table 4 Clinical and electromyographic performance of 5 patients with clinically possible ALS

\begin{tabular}{|c|c|c|c|c|c|c|c|c|}
\hline Cases & $\begin{array}{l}\text { Bulbar } \\
\text { muscle }\end{array}$ & $\begin{array}{l}\text { Cervical } \\
\text { muscle }\end{array}$ & $\begin{array}{l}\text { Thoracic } \\
\text { muscle }\end{array}$ & $\begin{array}{l}\text { Lumbosacral } \\
\text { muscle }\end{array}$ & UMN & & EMG & Diagnosis \\
\hline 29 & + & + & + & + & + & & + & Clinically definite \\
\hline 30 & + & + & + & + & + & & + & Clinically definite \\
\hline 31 & + & + & + & + & + & & + & Clinically definite \\
\hline 32 & + & + & + & + & + & & + & Clinically definite \\
\hline 33 & + & + & + & + & + & & + & Clinically definite \\
\hline 34 & + & + & + & - & + & & + & Clinically definite \\
\hline 35 & + & + & - & + & - & & + & Clinically definite \\
\hline 36 & + & + & + & + & + & & + & Clinically definite \\
\hline 37 & + & - & + & + & - & & + & Clinically definite \\
\hline 38 & + & + & - & + & + & & + & Clinically definite \\
\hline 39 & + & + & + & - & + & & + & Clinically definite \\
\hline 40 & + & + & + & + & + & + & & Clinically definite \\
\hline 41 & + & + & + & + & + & + & & Clinically definite \\
\hline 42 & + & + & + & + & + & + & & Clinically definite \\
\hline 43 & - & + & + & + & - & + & & Clinically definite \\
\hline 44 & - & + & + & + & - & + & & Clinically definite \\
\hline
\end{tabular}

The explanation is as shown in Table 1

\begin{tabular}{llllllll}
\hline Cases & $\begin{array}{l}\text { Bulbar } \\
\text { muscle }\end{array}$ & $\begin{array}{l}\text { Cervical } \\
\text { muscle }\end{array}$ & $\begin{array}{l}\text { Thorac- } \\
\text { icmuscle }\end{array}$ & $\begin{array}{l}\text { Lumbosa- } \\
\text { cral muscle }\end{array}$ & $\begin{array}{l}\text { UMN } \\
\text { EMG abnormal }\end{array}$ & $\begin{array}{l}\text { Symptomless muscle } \\
\text { EMiagnosis }\end{array}$ \\
\hline 45 & - & + & - & - & + & Limb muscles & Clinically probable \\
46 & - & - & - & + & - & Limb muscles & Clinically probable \\
47 & + & - & - & - & + & Upper limb muscles & Clinically probable \\
48 & - & + & - & - & - & T10 paraspinal muscle & Clinically probable \\
49 & + & + & - & - & + & + & Clinically probable \\
50 & - & + & - & + & - & + & Clinically probable \\
51 & - & + & - & + & - & + & Clinically probable \\
\hline
\end{tabular}

The explanation is as shown in Table 1

\begin{tabular}{llllllll}
\hline Cases & $\begin{array}{l}\text { Bulbar } \\
\text { muscle }\end{array}$ & $\begin{array}{l}\text { Cervical } \\
\text { muscle }\end{array}$ & $\begin{array}{l}\text { Thoracic } \\
\text { muscle }\end{array}$ & $\begin{array}{l}\text { Lumbosacral } \\
\text { muscle }\end{array}$ & UMN & EMG & Diagnosis \\
\hline 52 & + & - & - & - & - & + & Clinically possible \\
53 & + & - & - & + & \pm & + & Clinically possible \\
54 & - & + & - & - & + & + & Clinically possible \\
55 & - & + & - & - & - & + & Clinically possible \\
56 & - & + & - & - & - & + & Clinically possible \\
\hline
\end{tabular}

The explanation is as shown in Table 1 with EMG abnormalities while clinical asymptomatic (8 cases of cervical spinal cord group), and the highest rate of abnormality was $42.15 \%$. The EMG abnormal rate in deltoid was higher than that in biceps brachii of upper limb. The EMG abnormal rate of asymptomatic distal muscles of upper limb and lower limb were all similar. The EMG abnormal rate of trapezius appears to be higher than that of sternocleidomastoid in bulbar asymptomatic muscles (Table 8).

\subsubsection{Electrophysiological conduction}

The main abnormality of motor nerve conduction in this group of patients with ALS was the decrease of the median 
Table 5 Initial age of 56 patients with ALS in different onset groups $(\bar{X} \pm \mathrm{S})$

\begin{tabular}{lll}
\hline Onset group & Cases & $\begin{array}{l}\text { Initial age of } \\
\text { onset (year) }\end{array}$ \\
\hline Bulbus medullae group & 13 & $56.2 \pm 13.0$ \\
Cervical spinal cord group & 30 & $54.3 \pm 8.6$ \\
Lumbosacral spinal cord group & 13 & $56.2 \pm 13.0$ \\
Initial age of onset in total number of cases & 56 & $52.5 \pm 12.0$ \\
\hline
\end{tabular}

Explanation: The age of patients with ALS in this group is 10-72, thoracic spinal cord incidence: 0 cases

Table 6 Diagnostic time of 53 patients with ALS in different onset groups (Md)

\begin{tabular}{llc}
\hline Onset group & Cases & $\begin{array}{l}\text { Diagnosis } \\
\text { time (month) }\end{array}$ \\
\hline Bulbus medullae group & 12 & 8.0 \\
Cervical spinal cord group & 28 & 12.5 \\
Lumbosacral spinal cord group & 13 & 30.0 \\
Total diagnosis time & 56 & 12.5 \\
\hline
\end{tabular}

Table 7 Diagnostic Time of 53 patients with ALS in different age groups (Md)

\begin{tabular}{lll}
\hline Age group (years) & Cases & $\begin{array}{l}\text { Diagnosis } \\
\text { time (month) }\end{array}$ \\
\hline $10-39$ & 6 & 30.5 \\
$40-49$ & 9 & 12.0 \\
$50-59$ & 24 & 12.0 \\
$60-72$ & 14 & 17.5 \\
\hline
\end{tabular}

Table 8 Electromyography of neuromuscular damage in asymptomatic muscles of 53 patients with ALS

\begin{tabular}{llcr}
\hline Muscle & $\begin{array}{l}\text { Muscle } \\
\text { number }\end{array}$ & $\begin{array}{l}\text { Abnormal } \\
\text { case }\end{array}$ & $\begin{array}{l}\text { Abnormal } \\
\text { rate (\%) }\end{array}$ \\
\hline Deltoid & 36 & 11 & 30.60 \\
Biceps brachii & 51 & 8 & 15.70 \\
APB & 59 & 9 & 15.30 \\
ADM & 34 & 2 & 5.90 \\
FDI & 45 & 6 & 13.30 \\
T10 paraspinal muscle & 26 & 12 & 42.15 \\
Quadriceps & 55 & 6 & 9.10 \\
TA & 59 & 13 & 22.00 \\
MG & 38 & 10 & 26.30 \\
Trapezius & 18 & 5 & 27.80 \\
Sternocleidomastoid & 42 & 3 & 7.00 \\
Lingualis & 20 & 0 & 0.00 \\
\hline
\end{tabular}

amplitude of dCMAP. The median dCMAP latency of the ulnar nerve in different onset groups was prolonged. The median of dCMAP conduction velocity of limbs nerve was normal. Comparison of motor nerve conduction in different onset groups showed that the median amplitude of dCMAP in the median nerve of different onset groups was lower than the lower limit of normal, while the median amplitude of dCMAP in ulnar nerve was higher than normal. Electrophysiological characteristics of "split hands" were present in different onset groups: $85.7 \%$ in cervical spinal cord group, $45 \%$ in bulbus medullae group, and $41 \%$ in lumbosacral spinal cord group (Table 9). The median dCMAP amplitude of the peroneal nerve in lumbosacral spinal cord group was lower than the lower limit of normal, while the median of dCMAP amplitude in tibial nerve was higher than normal (Table 10).10\% of patients had sensory neurophysiological abnormalities in this group of patients with ALS.

\section{Discuss}

\subsection{The pathogenesis of ALS}

\subsubsection{Genetics}

The pathogenesis of ALS is unclear. Genetic research currently is a hot topic and potential drug treatment targets can be found. To date, more than 20 genes have been identified as pathogenic or highly related genes for ALS. These genes work together to address the pathogenesis of ALS, resulting in protein abnormal accumulation or defects in protein clearance pathways that eventually lead to mitochondrial balance dysfunction, RNA and DNA damaged, impaired cytoskeletal integrity, and altered axon transport motility (Chia et al. 2018). Current research on Chinese patients with ALS shows that SOD1 mutations account for $25.3 \%$ of Chinese fALS cases, being identified as the most frequently mutated ALS genes in China, followed by TARDBP (5.8\%) and FUS (5.8\%) (Liu et al. 2018). The following are three common ALS-related gene mutations and their pathological features and possible drug treatment.

4.1.1.1 SOD1 (Cu/Zn superoxide dismutase) The current research on SOD1 mutations and possible drug treatments are as follows: SOD1 protein is an antioxidant, SOD1 in patients with SOD1-ALS loses its own enzyme activity, so drugs that scavenge oxidizing free radicals have a therapeutic effect on ALS (Watanabe et al. 2018). Edaravone can antagonize oxidative free radicals and can inhibit the damage of vascular endothelial cells and astrocytes induced by oxidative stress and thus protect the motor neurons (Watanabe et al. 2018; Takei et al. 2017). It improves the decline of motor function in ALS patients and delays the progres- 
Table 9 The median nerve and ulnar nerve motor nerve conduction values in 56 ALS patients with different onset (median)

\begin{tabular}{|c|c|c|c|c|}
\hline \multirow[t]{2}{*}{ Onset group } & \multicolumn{2}{|l|}{ Median nerve } & \multicolumn{2}{|l|}{ Ulnar nerve } \\
\hline & $\begin{array}{l}\text { Latency/normal } \\
\text { value }(\mathrm{ms})\end{array}$ & $\begin{array}{l}\text { Amplitude/nor- } \\
\text { mal value }(\mathrm{mV})\end{array}$ & $\begin{array}{l}\text { Latency/normal } \\
\text { value }(\mathrm{ms})\end{array}$ & $\begin{array}{l}\text { Amplitude/ } \\
\text { normal value } \\
(\mathrm{mV})\end{array}$ \\
\hline Bulbus medullae group & $3.56 / 4.00$ & $5.60 / 5.00$ & $3.80 / 3.10$ & $8.00 / 5.00$ \\
\hline Cervical spinal cord group & $3.79 / 4.00$ & $2.60 / 5.00$ & $3.20 / 3.10$ & $5.50 / 5.00$ \\
\hline Lumbosacral spinal cord group & $3.80 / 4.00$ & $6.70 / 5.00$ & $3.20 / 3.10$ & $8.30 / 5.00$ \\
\hline
\end{tabular}

Normal value: According to the normal value of motor nerve conduction (clinical neuroelectrophysiology) compiled by Professor Cui Liying combined with the value of patients with normal motor nerve conduction examined in the laboratory for more than 10 years

\begin{tabular}{|c|c|c|c|c|}
\hline \multirow[t]{2}{*}{ Onset group } & \multicolumn{2}{|l|}{ Peroneal nerve } & \multicolumn{2}{|l|}{ Tibial nerve } \\
\hline & $\begin{array}{l}\text { Latency/normal } \\
\text { value }(\mathrm{ms})\end{array}$ & $\begin{array}{l}\text { Amplitude/nor- } \\
\text { mal value }(\mathrm{mV})\end{array}$ & $\begin{array}{l}\text { Latency/normal } \\
\text { value }(\mathrm{ms})\end{array}$ & $\begin{array}{l}\text { Amplitude/ } \\
\text { normal value } \\
(\mathrm{mV})\end{array}$ \\
\hline Bulbus medullae group & $3.77 / 4.90$ & $4.00 / 3.00$ & $3.50 / 5.80$ & $13.50 / 4.00$ \\
\hline Cervical spinal cord group & $4.00 / 4.90$ & $4.50 / 3.00$ & $3.60 / 5.80$ & $15.40 / 4.00$ \\
\hline Lumbosacral spinal cord group & $4.00 / 4.90$ & $0.90 / 3.00$ & $3.80 / 5.80$ & $14.90 / 4.00$ \\
\hline
\end{tabular}

Normal value: According to the normal value of motor nerve conduction (clinical neuroelectrophysiology) compiled by Professor Cui Liying combined with the value of patients with normal motor nerve conduction examined in the laboratory for more than 10 years
Table 10 The peroneal nerve and tibial nerve motor nerve conduction values in 56 ALS patients with different onset (median) lism and is also a polyglutamine protein essential for SG assembly, reducing TDP-43 aggregates and their neurotoxicity (Gao and Wang 2018; Becker et al. 2017).

4.1.1.3 FUS (fused in sarcoma protein) FUS is physiologically involved in RNA metabolism and DNA repair, and there are indications that DNA damage is apparent in FUS-ALS. FUS is normally shuttled between the nucleus and cytoplasm, mainly in the nucleus, and nuclear transport is impaired in patients with FUS-ALS, resulting in mislocalization of FUS in the cytoplasm, self-assembly in the cytoplasm and subsequent neurodegeneration and FUS aggregate formation (Matsumoto et al. 2018; De Santis et al. 2017). FUS aggregates promote the secretion of tumor necrosis factor-Alpha $(\mathrm{TNF} \alpha)$ and thus alter the expression level of AMPA receptors (which mediates glutamate excitatory overexpression), making motoneurons more sensitive to stimuli and leading to excitotoxic damage and cell death, the AMPA-mediated excitotoxic component pathway serves as a potential therapeutic target for FUS-ALS (Kia et al. 2018). Therefore, it is possible to neutralize soluble TNF $\alpha$ or to block glutamate excitatory transmission to reduce damage to neuronal cells. The current TNF $\alpha$ inhibitor thalidomide shows some promising results in animal models of FUS-ALS but does not appear to be effective in regulating disease progression in patients (Kia et al. 2018). Riluzole blocks glutamate-mediated excitatory neurotransmission to reduce excitotoxicity and is currently the only drug of life to prolong ALS patients (Introna et al. 2018). 
4.1.1.4 Genotype and clinical phenotype Patients with ALS have a wide range of clinical and genetic variability (Koroglu et al. 2017). Such as age of onset (AAO), clinical features, progression patterns, involvement of FTD, genetic patterns ( $\mathrm{Li}$ and $\mathrm{Wu} 2016$ ).

fALS can be used as dominant, recessive, or X-linked inheritance, but the most common type is autosomal dominant inheritance in adults, and autosomal recessive inheritance is rare in adolescents (Yamashita and Ando 2015). ALS usually develops later in life and the average AAO is 65 years old. AAO in fALS is earlier than sALS. A small percentage of patients may have juvenile onset (JALS), with AAO occurring before age 20 ( $\mathrm{Li}$ and $\mathrm{Wu} 2016$ ).

Studies of ALS patients in China showed that most of the SOD1 gene mutations were dominantly inherited (Liu et al. 2018; Li and Wu 2016; Goutman et al. 2018). Most SOD1-ALS are progressing rapidly, and AAO and severity may vary greatly. The survival of SOD1-ALS is highly variable $(<3$ years or $>10$ years). The onset area is often characterized by prominent LMN injury, and UMN signs may be difficult to detect (Yamashita and Ando 2015; Goutman et al. 2018).

Patients with TDP-43-ALS have a typical phenotype compared with sALS, mainly upper limb disease (60.7\%) and longer disease duration (63.0 months), and TDP-43ALS patients in Asian have 58.8\% of bulbus medullae group. Most patients did not have obvious dementia, and AAO of TDP-43-ALS was earlier ( $\mathrm{Li}$ and $\mathrm{Wu}$ 2016; Yamashita and Ando 2015).

The clinical phenotype of FUS-ALS includes adult-onset ALS, JALS, ALS-FTD, and a single FTD and is rare. Compared with SOD1-ALS, patients with FUS-ALS had earlier AAO (approximately 45 years of age), more common in bulbus medullae group and rapid progression (average survival of 30-33 months). AAO of JALS is less than 25 years old and survives as short as 1 year. The LMN injury of the upper or lower limbs in the first site is dominant ( $\mathrm{Li}$ and $\mathrm{Wu} 2016$; Yamashita and Ando 2015; Goutman et al. 2018).

C9ORF72-ALS has a typical phenotype of ALS, and the first site begins with the upper or lower limbs including UMN and LMN injuries. Compared with sALS and other gene mutations, C9ORF72-ALS has a higher incidence of bulbus medullae and FTD (Goutman et al. 2018). And the median survival time was shorter than that of TDP-43-ALS or SOD1-ALS (Li and Wu 2016).

\subsubsection{Protein solidification system}

The presence of protein aggregates in motor neurons and glial cells in patients with fALS and sALS reflects the dysfunction of these protein quality-controlling degradation pathways. Abnormal aggregates of proteins have resistance to all known proteolytic pathways ( $\mathrm{Li}$ and $\mathrm{Wu} 2016$;
Ciechanover and Kwon 2015). Including molecular chaperones, autophagy, ubiquitin proteasome system (UPS), endoplasmic reticulum-associated degradation (ERAD) and so on.

Increasing the clearance rate of protein aggregates is also raising the levels of chaperones, UPS, and autophagy. Increasing the clearance rate of protein aggregates is also raising the levels of chaperones, UPS, and autophagy. AMPK-mTOR-ULKl/2 is the main pathway of autophagy, and AMPK activators such as thienopyridine, benzimidazole, and aspirin (which can be activated directly in combination with AMPK) can promote autophagy (José and Ortiz 2012). Other autophagy regulators such as the atypical serine/threonine kinase (mTOR) inhibitor rapamycin also promote autophagy, so the promotion of autophagy is also actively being developed as a potential drug target (Ciechanover and Kwon 2015).

\subsubsection{Oxidative stress}

The body's normal metabolism produces byproducts of oxyradical, which irreversibly damage intracellular biomolecules such as DNA, RNA, proteins, and lipids. The levels of oxyradical in the body are controlled, such as SOD1, catalase, glutathione, peroxidase and various types of superoxide dismutase, etc (Rafael et al. 2017). Oxidative stress biomarkers in cerebrospinal fluid, plasma, and urine of patients with SOD1-ALS, other gene mutations in ALS, and sALS are elevated, suggesting that oxidative stress injury in ALS patients is not a single cause of mutations in SOD1 gene and may have other genes mutation or other ways (DeCoteau et al. 2016). One currently accepted drug for the treatment of ALS is edaravone. Other antioxidants such as cerium oxide nanoparticles (CeNPs) neutralize reactive oxygen species and nitrogen compounds. These nanoparticles can enter the central nervous system with relatively long half-lives. Current cerium oxide nanoparticles (CeNPs) are used in ALS antioxidant treatment. It has been used in animal models and demonstrated to prolong the survival of SOD1-ALS mice (DeCoteau et al. 2016).

\subsubsection{Mitochondrial abnormalities}

Mitochondria are produced in the neuronal soma, and mitochondrial anterograde axon transport is mediated by kinesin-1, and retrograde transport is mediated by cytoplasmic dynein. Kinesin-1 and cytoplasmic dynein fulfill mitochondrial transport through interaction with the mitochondrial in vitro-model protein Rho GTPase 1 (Miro1) and transporter kinesin (TRAK) 1 and 2 (Moller et al. 2017). The expression of Miro1 was significantly decreased in the spinal cord of SOD1-ALS and TDP-43-ALS patients, thus indicating the possibility that Miro1 down-regulation may 
result in abnormal mitochondrial transport in ALS motor neurons (Gao et al. 2017). Studies have found that mitochondrial accumulation in the cell bodies and shafts of spinal motoneurons in patients with sALS (Vandoorne et al. 2018; Magrané et al. 2014).

Histone deacetylase 6 (HDAC6) inhibitors increase $\alpha$-tubulin acetylation and restore mitochondrial axonal transport defects as potential therapeutic agents (Guo et al. 2017).

\subsection{The clinical characteristics of patients with ALS}

The onset age of ALS patients in this group was $52.5 \pm 12.0$, which was earlier than reported in foreign countries (Nzwalo et al. 2014). Cui Liying's epidemiological study of 710 patients in a single center published by the Association of ALS in 2017 had showed that the average onset age of ALS patients in our country is about 53 , younger than that of foreign patients, but similar to this group. The incidence of lumbosacral spinal cord in this group patients with ALS was younger than that of the bulbus medullae and cervical spinal cord group. The incidence of cervical spinal cord was 48.2\%, it was consistent with foreign reports (Nzwalo et al. 2014). The incidence of cervical spinal cord was significantly higher than in the bulbus medullae and lumbosacral spinal cord.75\% of the cases in the cervical spinal cord group were distal episodes of the upper limbs. Human activities were mainly concentrated in the distal of the upper limbs, and oxidative stress accumulation significant damage was observed. The nerve fibers of the distal muscles are long, and the mitochondria axon transport disorder is the first to involve the distal muscles. Males with onset of bulbus medullae were more common than females in this group. Contrary to most studies, bulbus medullae onset cases were fewer in this group. Atypical cases accounted for $7.1 \%$ of this group, similar to previously reported atypical symptoms (Bäumer et al. 2014). These atypical symptoms make it difficult to identify in early ALS, which makes early diagnosis of ALS difficult.

\subsection{The diagnosis time of ALS patients}

Because the pathogenesis of ALS is unclear, it is a rare disease and early clinical manifestations are hidden (Bäumer et al. 2014). These factors bring difficulties for the early diagnosis of ALS, which leads to the extension of the diagnosis time of ALS. Foreign studies on the diagnosis time of ALS show that the average diagnosis time of ALS is 10.1-12.5 months (Nzwalo et al. 2014; Galvin et al. 2017). Domestic studies suggest that the diagnosis time of ALS is (16.9 \pm 15.5$)$ months (Guo and Shang 2010). The median time of diagnosis in this group of patients with ALS was 12.5 months, which was consistent with the foreign reports (Nzwalo et al. 2014; Galvin et al. 2017).
The study on the potential impact factors of diagnosis time in foreign countries mostly focuses on the age of onset, the first symptom, the first site, the number and specialty of the doctors before the diagnosis, and the diagnosis of misdiagnosis (Paganoni et al. 2014; Simon et al. 2014; Chen and Fan 2014; Cellura et al. 2012). The studies in foreign believe that the older the initial age, the longer the diagnosis time, which may be due to the rapid progression of ALS in elderly patients (Paganoni et al. 2014). The diagnosis time of first site in the bulbus medullae is shorter than that of in the spinal cord. This may be related to the rapid progression of the bulbus medullae in ALS (Piaceria et al. 2018). This group of patients with ALS have a longer diagnosis time at the initial age $\geq 60$ years, contrary to the results reported by foreign countries (Nzwalo et al. 2014). It was also found that the initial age $\geq 60$ years accounted for $64.3 \%$ of the first misdiagnosis, in which $77.8 \%$ patients was misdiagnosed as cerebral infarction, so the majority of the reasons for prolonged diagnosis of older patients may be misdiagnosis. The bulbus medullae group has a shorter definite diagnosis time. The study in foreign on the factors of the number of doctors at the diagnosis time found that some patients had visited other professional doctors (orthopedic surgeons, otolaryngology doctors, neurosurgeons, etc) before clinically definite, and the more number of doctors visited before clinically definite, non-neurologist is known little about ALS, the longer diagnosis time for final referral to a neurologist, resulting in longer diagnostic time (Paganoni et al. 2014). Therefore, it is possible to identify some of the easily recognizable symptoms in ALS, such as the phenomenon of "split hands" as a "warning" of the ALS so that non-neurologists will immediately refer patients to a neurologist. How can we improve non-neurologists' understanding of ALS? Can be used as a research question. There was a significant negative correlation between the initial age of ALS and the average diagnosis time in domestic research, indicating that the older initial age, the shorter diagnosis time is, presumably because the older initial age, the faster the disease progresses (Guo and Shang 2010). This is consistent with the results of foreign studies. At present, there are few studies on other potential influence factors of ALS diagnostic time in China.

The Awaji-shima diagnostic criteria were proposed in 2006. This diagnostic criteria indicates that clinical manifestations and electromyographic charts are equally important in the diagnosis of LMN (Electromyography 2012). This group of patients with ALS were performed electromyographic examination of early clinical diagnosis level of 12 cases, accounting for $21.42 \%$ of the total number of cases. Although there are new findings in the ALS study, the diagnosis time of ALS has not changed significantly in the past 10 years and it is still $8-10$ months (Smith et al. 
2017). Therefore, it is important to clarify the diagnostic time of ALS and its potential impact factors for the doctor to diagnose ALS.

\subsection{Nerve electrophysiological examination}

Awaji-shima diagnostic criteria indicates that clinical manifestations and electromyography are equally important in the diagnosis of LMN (Furuta et al. 2013). However, studies have found that when one-third of motor fibers degenerate, clinical weakness becomes apparent (José and Ortiz 2012). There is some difficulty in clinical diagnosis when there is damage to the LMN without clinical manifestations. There are $57.14 \%$ patients with asymmetry of clinical and electrophysiological abnormalities in our study, higher than that of $40 \%$ in foreign studies (Gao et al. 2017). The proportion of EMG abnormalities in the asymptomatic muscles of the upper and lower limbs is very high, which is related to the intensity of human activities mainly concentrated in the upper and lower limbs, which increases the oxidative stress of LMN and accelerates the damage of LMN. The final cause of death in patients with ALS is respiratory failure. The onset of thoracic spinal cord in this group patients with ALS was 0 cases, a total of 26 patients underwent T10 paraspinal muscle EMG examination showed 12 cases of patients with asymptomatic EMG abnormalities, the abnormal rate was $42.15 \%$. This takes into account that muscle strength may be preserved by collateral sprouting in the early stages of LMN injury, and clinical weakness appears to be a failure of these compensatory mechanisms (Zefeng and Liying 2010). Therefore, electrophysiological assessment becomes an indispensable part of the diagnosis. In particular, extensive EMG screening during sub-clinical performance is worthy of recommendation and can provide early diagnosis.

Nerve conduction studies found that the median amplitude of dCMAP in median nerves in the cervical spinal cord group was lower than the lower limit of normal, while the median amplitude of dCMAP in ulnar nerves was greater than normal values. Electrophysiological characteristics of "split hands" existed in all onset groups, however it's up to $85.7 \%$ in the cervical spinal cord. Electrophysiological evidence of "split hands" in the bulbus medullae group and lumbosacral spinal cord group were up to $40 \%$, combined with $15.3 \%$ of denervated performance of EMG in the median nerve (APB) is asymptomatic and denervation in the ulnar nerve (ADM) was $4.9 \%$. It was more likely to indicate that the median nerve is more sensitive to ALS damage. Therefore, early neurophysiological examinations in the clinical suspicion of ALS look for early evidence of "split hands" to provide evidence for the early diagnosis of ALS. The median latency of ulnar nerve dCMAP in different onset groups was greater than the normal value, which was related to the damage of fast conduction fiber axons in ulnar nerve. The median dCMAP amplitude of the peroneal nerve in the lumbosacral spinal cord group was lower than the lower limit of normal, whereas the median amplitude of dCMAP in sacral nerve was greater than normal, indicating that for the lower limbs, the peroneal nerve was more sensitive than the sacral nerve to ALS.

When clinical considerations are ALS, a neurophysiological examination is required to confirm that the clinically affected area is a lesion of the LMN, and we can find that there is also a motor neuron lesion in the non-clinical region, while excluding other diseases (Furuta et al. 2013). In summary, the significance of electromyography is early diagnosis and elimination of diagnosis. However, the diagnostic sensitivity of EMG is only 60\% (Bäumer et al. 2014). Although the standard of electrophysiology standard is improved in the Awaji-shima diagnostic criteria, how to improve the sensitivity of neural electrophysiology to early ALS is also the key to early diagnosis of ALS.

Open Access This article is distributed under the terms of the Creative Commons Attribution 4.0 International License (http://creativeco mmons.org/licenses/by/4.0/), which permits unrestricted use, distribution, and reproduction in any medium, provided you give appropriate credit to the original author(s) and the source, provide a link to the Creative Commons license, and indicate if changes were made.

\section{References}

Bäumer D, Talbot K, Turner MR (2014) Advances in motor neurone disease. J R Soc Med 107(1):14-21

Becker LA, Huang B, Bieri G (2017) Therapeutic reduction of ataxin 2 extends lifespan and reduces pathology in TDP-43 mice. Nature 544 (7650):367-371

Bond L, Bernhardt K, Madria P (2018) A metadata analysis of oxidative stress etiology in preclinical amyotrophic lateral sclerosis: benefits of antioxidant therapy. Front Neurosci 24:12-10

Cellura E, Spataro R, Taiello AC (2012) Factors affecting the diagnostic delay in amyotrophic lateral sclerosis. Clin Neurol Neurosurg 114(6):550-554

Chen Y, Fan D (2014) Natural history and clinical features of amyotrophic lateral sclerosis. Chin J Internal Med 53(9):752-753

Chia R, Chiò A, Traynor BJ (2018) Novel genes associated with amyotrophic lateral sclerosis: diagnostic and clinical implications. Lancet Neurol 17:94-102

Ciechanover A, Kwon TY (2015) Degradation of misfolded proteins in neurodegenerative diseases: therapeutic targets and strategies. Exp Mol Med 47:e147

De Santis R, Santini L, Colantoni A (2017) FUS mutant human motoneurons display altered transcriptome and microRNA pathways with implications for ALS pathogenesis. Stem Cell Rep 14(5):1450-1462 9

DeCoteau W, Heckman KL, Estevez AY (2016) Cerium oxide nanoparticles with antioxidant properties ameliorate strength and prolong life in mouse model of amyotrophic lateral sclerosis. Nanomedicine 12 (8):2311-2320

Electromyography and Clinical Neurophysiology Group of Chinese Academy of Neurology Branch, Neuromuscular Group of 
Neurology Branch of Chinese Medical Association (2013) Guidelines for the diagnosis and treatment of amyotrophic lateral sclerosis in China. Chin J Neurol 45(7):531-533

Furuta N, Makioka K, Fujita Y (2013) Changes in the clinical features of amyotrophic lateral sclerosis in rural Japan. Intern Med 52(15):1691-1696

Gabriel ET, Ecroyd H, Dianne F (2018) Assessment of metal concentrations in the SOD1G93A mouse model of amyotrophic lateral sclerosis and its potential role in muscular denervation, with particular focus on muscle tissue. Mol Cell Neurosci 88:319-329

Galvin M, Gaffney R, Corr B (2017) From first symptoms to diagnosis of amyotrophic lateral sclerosis:perspectives of an Irish informal caregiver cohort-a thematic analysis. BMJ Open 7:e014985

Gao J, Wang L, Liu J (2017) Abnormalities of mitochondrial dynamics in neurodegenerative diseases. Antioxidants (Basel) 6(2):25

Gao J, Wang L, Huntley ML, Perry G, Wang X (2018) Pathomechanisms of TDP-43 in neurodegeneration. J Neurochem. https://doi. org/10.1111/jnc. 14327

Goutman SA, Chen KS, Paez-Colasante X (2018) Emerging understanding of the genotype-phenotype relationship in amyotrophic lateral sclerosis. Handb Clin Neurol 148:603-623

Guo X, Shang H (2010) Clinical characteristics of patients with sporadic amyotrophic lateral sclerosis in Southwest China. Chin J Neuropsychiatry 46(5):296-299

Guo W, Naujock M, Fumagalli L (2017) HDAC6 inhibition reverses axonal transport defects in motor neurons derived from FUS-ALS patients. Nat Commun 11(1):861 8

Introna A, DErrico E, Modugno B (2018) Adherence to riluzole in patients with amyotrophic lateral sclerosis: an observational study. Neuropsychiatr Dis Treatm 14:193-203

José M, Ortiz M (2012) The ancient drug salicylate directly activates AMP-activated protein kinase. Science 18 336(6083):918-922

Kia A, McAvoy K, Krishnamurthy K (2018) Astrocytes expressing ALS-linked mutant FUS induce motor neuron death through release of tumor necrosis factor-alpha. Neurosciences 66:1016-1033

Koroglu C, Ylmaz R, Sorgun MH (2017) GNE missense mutation in recessive familial amyotrophic lateral sclerosis. Neurogenetics $18: 237-243$

Li HF, Wu ZY (2016) Genotype-phenotype correlations of amyotrophic lateral sclerosis. Transl Neurodegener 5:3

Liu X, He F Gao FB (2018) The epidemiology and genetics of amyotrophic lateral sclerosis in China. Brain Res 02:035

Magrané J, Cortez C, Gan WB (2014) Abnormal mitochondrial transport and morphology are common pathological denominators in SOD1 and TDP43 ALS mouse models. Hum Mol Genet 23(6):1413-1424

Matsumoto T, Matsukawa K, Watanabe N (2018) Self-assembly of FUS through its low-complexity domain contributes to neurodegeneration. Hum Mol Genet 27(8):1353-1365

Moller A, Bauer CS, Cohen RN (2017) Amyotrophic lateral sclerosis-associated mutant SOD1 inhibits anterograde axonal transport of mitochondria by reducing Miro1 levels. Hum Mol Genet 26(23):4668-4679
Nicholas JM (2017) What can we learn from the edaravone development program for ALS? Amyotroph Lateral Scler Frontotemp Degener 18:98-103

Nzwalo H, de Abreu D, Swash M (2014) Delayed diagnosis in ALS: the problem continues. J Neurol Sci 343:173-175

Paganoni S, Macklin EA, Lee A (2014) Diagnostic timelines and delays in diagnosing amyotrophic lateral sclerosis (ALS). Amyotroph Lateral Scler Frontotemp Degener 15 (5-6):453-456

Piaceria I, Bessib V, Mata S (2018) Association of the new variant Tyr424Asp at TBK1 gene with amyotrophic lateral sclerosis and cognitive decline. J Alzheimer's Dis 61:41-46

Rafael H, David JO, Vilca A (2017) Etiology and treatment of amyotrophic lateral sclerosis. Am J Neurodegener Dis 6(1):1-8

Sabrina P, Macklin E, Alexandra L (2014) Diagnostic timelines and delays in diagnosing amyotrophic lateral sclerosis (ALS). Amyotroph Lateral Scler Frontotemporal Degener 15:453-456

Simon NG, Lomen-Hoerth C, Kiernan MC (2014) Patterns of clinical and electrodiagnostic abnormalities in early amyotrophic lateral sclerosis. Muscle Nerve 50(6):894-899

Smith EF, Shaw PJ, De Vos KJ (2017) The role of mitochondria in amyotrophic lateral sclerosis. Neurosci Lett S0304-3940(17):30544-X

Takei K, Watanabe K, Yuki S (2017) Edaravone and its clinical development for amyotrophic lateral sclerosis. Amyotroph Lateral Scler Frontotemp Degener 18:5-10

Tokuda E, Nomura T, Ohara S (2018) A copper-deficient form of mutant cu/Zn-superoxide dismutase as an early pathological species in amyotrophic lateral sclerosis. BBA Mol Basis Dis 1864:2119-2130

Vandoorne T, De Bock K, Van Den Bosch L (2018) Energy metabolism in ALS: an underappreciated opportunity? Acta Neuropathol 135(4):489-509

Watanabe K, Tanaka M, Yuki S (2018) How is edaravone effective against acute ischemic stroke and amyotrophic lateral sclerosis? Clin Biochem 62(1):20-38

Weskamp K, Barmada SJ (2018) TDP43 and RNA instability in amyotrophic lateral sclerosis. Brain Res 01:015

Wobst HJ, Chadchankar J (2017) Cytoplasmic relocalization of TAR DNA-binding protein 43 is not sufficient to reproduce cellular pathologies associated with ALS in vitro. Front Mol Neurosci 24:10-46

Yamashita S, Ando Y (2015) Genotype-phenotype relationship in hereditary amyotrophic lateral sclerosis. Transl Neurodegener 4:13

Zefeng C, Liying C (2010) Discussion on the evaluation of muscular strength grading. Chin J Neurol 43:86

Publisher's Note Springer Nature remains neutral with regard to jurisdictional claims in published maps and institutional affiliations. 